\title{
FIOS DE SIGNIFICAÇÃO RECONHECIDOS E REORIENTADOS NO PROCESSO DE TRADUCC̃̃O DE LITERATURA - PORTUGUÊS/LIBRAS
}

\author{
The construction of meaning, recognized and reoriented, in the process of literature \\ translation: Portuguese/Libras language
}

La construcción de significado, reconocido y reorientado, en el proceso de traducción de literatura: idioma Portugués/idioma Libras

\author{
Neiva Aqui Albres ${ }^{1}$ \\ Mairla P. Pires Costa ${ }^{2}$ \\ Harrison Gerotto Adams ${ }^{3}$
}

\begin{abstract}
Resumo
Este artigo aborda o processo de construção de sentidos em tradução com o objetivo de mostrar o papel de leitor e de produtor de novos enunciados em atividades de tradução, ao analisar trechos de traduções realizadas com os alunos do Curso de Letras Libras, da Universidade Federal de Santa Catarina (UFSC). O texto parte de uma discussão da contribuição do pensamento bakhtiniano às Ciências Humanas, no tocante ao discurso, à atividade, ao sujeito e à subjetividade. A partir da descrição de trechos da tradução e detalhando as escolhas tradutórias, evidencia-se a utilização do espaço-sub-rogado, a construção do sentido não somente pelas palavras que compõem o texto escrito, mas, também pelas ilustrações que fazem parte da obra. Concluímos, como resultado de pesquisa, que apesar do projeto enunciativo do tradutor ser diferente, garante-se o processo de construção de sentidos.
\end{abstract}

PALAVRAS-CHAVE: Tradução. Sentido. Libras.

\begin{abstract}
This article discusses the senses construction process of translation in order to show the role of player and producer of new enunciation in translation activities, analyzing stretches of translations carried out with Libras Language undergraduate students at Federal University of Santa Catarina (UFSC). The text starting from a discussion of the Bakhtin's contribution to the Human Sciences, with regard to discourse, the activity, the subject and subjectivity. From the description of the translation sections and detailing the translational choices, highlights the use of space-subrogated, the construction of meaning not only by words of the written text, but also the illustrations that are part of the work. We conclude, as a result of research, that

\footnotetext{
${ }^{1}$ Doutora em Educação Especial pela Universidade Federal de São Carlos - UFSCar ( 2010- 2013 - Bolsa CNPQ). MESTRADO em Educação pela Universidade Federal de Mato Grosso do Sul - UFMS (2005 - Bolsa CAPES). Especialização em Psicopedagogia pela Universidade para o Desenvolvimento da Região do Pantanal - UNIDERP (2005). Graduação em Normal Superior pela Universidade Estadual de Mato Grosso do Sul UEMS (2003) e graduação em Fonoaudiologia pela Universidade Católica Dom Bosco - UCDB (1999). E-mail: neiva.albres@ufsc.br

${ }^{2}$ Graduanda Licenciatura Letras Libras Universidade Federal de Santa Catarina- UFSC. Graduada em

Biblioteconomia pela Universidade do Estado de Santa Catarina. Bibliotecária na Universidade Federal de Santa Catarina. E-mail: mairlapp@hotmail.com

${ }^{3}$ Graduando Licenciatura Letras Libras pela Universidade Federal de Santa Catarina - UFSC. Bolsista PIBIC/CNPQ. E-mail: harrisonadams2005@gmail.com
} 
despite the translator's declarative enunciation be different, ensures the process the construction of senses.

\section{KEYWORDS: Translation. Sense. Libras Language}

\section{Resumen}

Este artículo aborda el proceso de construcción de sentido que se da mediante la traducción con el fin de mostrar el papel de lector y productor de las nuevas declaraciones en las actividades de traducción, cuando se analiza tramos de traducciones realizadas con alumnos del Curso Letras Libras, de la Universidad Federal de Santa Catarina (UFSC). El texto parte de una contribución de la discusión del pensamiento de Bakhtin en Humanidades, en relación con el discurso, la actividad, el sujeto y la subjetividad. A partir de la descripción de las secciones de traducción y detallando las opciones de traslación, destaca el uso por la personificacion del espacio, la construcción de significado, no sólo por las palabras del texto escrito, sino también por las ilustraciones que forman parte de la obra. Llegamos a la conclusión, como resultado de la investigación, a pesar de las formas de decir del traductor pueden ser diferentes, se garantiza el proceso de construcción de sentido.

PALABRAS CLAVE: Traducción. Sentido. Idioma Libras

\section{INTRODUÇÃO}

Traduções para língua brasileira de sinais - Libras vêm gradativamente sendo publicadas no Brasil na medida em que os usuários da Libras se tornam presentes em diversos espaços e requerem materiais didáticos, acadêmicos ou literários em Libras (ALBRES, 2012, 2014a). Bem como em função das políticas de acessibilidade mediante a luta pelos direitos linguísticos (BRITO, 2013), que garantem o direito ao acesso a cultura e educação por meio de sua língua. Os textos traduzidos para língua sinalizada são produzidos basicamente em formato midiático (vídeo compondo um hipertexto), sendo que esse tipo de texto requer do tradutor a utilização de estratégias específicas, diferentes daquelas utilizadas em traduções de línguas orais produzidas apenas em formato escrito.

A tecnologia (sistemas eletrônicos de comunicação) que começa a ser desenvolvida no século XX influencia diretamente nosso comportamento e cultura, nossa forma de ver e de se relacionar com materiais didáticos e pedagógicos, propiciando novas práticas artísticoliterárias e pedagógicas, nas quais se hibridizam linguagens e suportes de diferentes esferas e se revela o caráter multimodal do uso da linguagem.

A escola deve possibilitar aos alunos várias práticas sociais que se utilizam da leitura e da escrita, de um letramento no plural, ou seja, de letramentos. Nessa perspectiva,

[...] é preciso considerar: os multiletramentos ou letramentos múltiplos, inclusive os letramentos das culturas locais e de seus agentes, colocando-os em contato com os letramentos valorizados, universais e institucionais; os letramentos multissemióticos, ampliando a noção de letramento para o campo da imagem, da música e das outras semioses que não somente a escrita (FIGUEIREDO; GUARINELLO, 2013, p. 177).

Textos multimodais podem auxiliar na educação de surdos. Gesueli e Moura (2006, p, 120) atentam para a importância de "se conceber o letramento na surdez como um processo multimodal". "Multimodal é o gênero que apresenta a materialização em mais de uma forma: Nessa direção, um texto multimodal é caracterizado por uma apresentação textual que envolva palavras, imagens e sons, por exemplo," (FIGUEIREDO; GUARINELLO, 2013, p. 179). 
Segundo Figueiredo e Guarinello (2013)

\begin{abstract}
Na multimodalidade, a maioria dos textos envolve um complexo jogo entre textos escritos, cores, imagens, elementos gráficos e sonoros, o enquadramento, a perspectiva da imagem, espaços entre imagem e texto verbal, escolhas lexicais, com predominância de um ou de outro modo, de acordo com a finalidade da comunicação, sendo, portanto, recursos semióticos importantes na construção de diferentes discursos (FIGUEIREDO; GUARINELLO, 2013, p. 179).
\end{abstract}

Segundo Figueiredo e Guarinello (2013, p. 179), valer-se da multimodalidade no contexto da educação de surdos subsidia ao professor que empregue recursos visuais no processo de ensino e ainda, proporciona que o aluno interaja com os conteúdos e desenvolvimento seu letramento.

É importante destacar que tanto professores quanto tradutores que trabalham com literatura infanto-juvenil destinarão seu trabalho a alunos da educação básica que apresentam diferentes níveis de aquisição de língua de sinais, não sendo possível quantificar esse conhecimento. Trabalhamos, portanto, com um público em potencial. "Esse conhecimento, por sua vez, depende de fatores que vão além da escolarização do surdo, como o contato e a qualidade da interação que a criança teve e tem com essas línguas" (FIGUEIREDO; GUARINELLO, 2013, p. 179).

Materiais em línguas de sinais requerem mais ainda o uso de interfaces tridimensionais e digitais que contribuirão para a leitura de um público diverso. Iniciativas neste sentido podem ser vislumbradas com o projeto Argentino "Videolibros Virtuales" site em que adultos leem livros em Língua argentina de sinais (Lengua de Señas Argentina LSA) organizado pela Confederação Argentina de Surdos (CAS) e o projeto "Bilingual Storybook App" nos Estados Unidos da América da Universidade Gallaudet, com o projeto da Fundação Científica Nacional de aprendizagem visual (Visual Learning - VL2). Os dois projetos apresentam materiais bilíngues e tem como objetivo contribuir para o aprendizado e experiência leitora de crianças surdas, apresentando uma pessoa real usando a língua de sinais de cada país, animação e acompanhamento do texto escrito na língua do país envolvendo aspectos de leitura, tradução e contação da história.

Estudos sobre tradução de literatura infanto-juvenil vêm sendo desenvolvidos (ALBRES, 2012, 2014a, 2014b), focando os critérios para produção da tradução, a polifonia e dialogia no processo de tradução e criação da enunciação em Libras, aspectos verbo-visuais que motivam os tradutores para a criação da tradução. Estes estudos constataram que os tradutores são motivados pelas ilustrações e pelo texto para a criação do texto trazido em Libras, que o produto final em Libras carrega marcas das ilustrações do texto base e da subjetividade dos tradutores. Todavia, ainda há que se investigar se essa construção em Libras preserva o significado do texto base. Questões são levantadas nesta pesquisa: 1) Como os elementos verbo-visuais influenciam nas escolhas tradutórias no livro de literatura infantojuvenil? 2) Estes elementos auxiliam na construção da tradução e fornecem subsídios para recriar o texto mantendo a correspondência de sentido? 3) Que nível de distanciamento ou aproximação pode se estabelecer entre texto base e texto meta (traduzido)?

Traçamos como objetivo para este trabalho analisar uma tradução de livro infantil (Vira Lata), tendo como corpus o texto verbo-visual (português e ilustrações) e vídeo em

\footnotetext{
${ }^{4}$ Projeto "Videolibros Virtuales". Disponível em: <http://www.videolibroslsa.org.ar/>

${ }^{5}$ Informações sobre "Bilingual Storybook App" Disponível em:

$<$ http://www.gallaudet.edu/news/blue_lobster_app.html>
} 
Libras, com vistas a discutir de que modo uma tradução motivada por elementos verbovisuais corroboram para a construção de sentidos de um leitor surdo de livro de literatura infanto-juvenil.

\section{Construção de sentidos pelo tradutor: fios de significação e "Estudos da Tradução"}

A tradução como ato empírico passa a ser estudada pelos estudos literários, depois pelos estudos linguísticos, até que galga sua independência com a definição do campo disciplinar "Estudos da Tradução" na década de 1970 (VASCONCELLOS, 2010). Apesar dos primeiros pensadores da temática datarem de 100 a.C. como Cícero, Horário e São Jerônimo, a sistematização propriamente dita do assunto ocorre apenas no século XIX (AGUIAR, 2000).

A concepção do que é tradução foi mudando com o decorrer dos estudos, sendo que os teóricos ainda apresentam divergências de conceituação. Segundo Souza, "o modo de conceituar tradução varia, de acordo com a polissemia do termo e com as diferentes perspectivas dos teóricos da tradução" (SOUZA, 1998, p. 51). Seja por especificar o conceito a partir de uma vertente, seja por enfatizar determinados aspectos, as teorias de tradução vão se construindo ao longo do tempo e oferecendo posicionamentos diversificados. Enquanto alguns estudiosos estão focados na descrição linguística, outros se atém a aspectos neurológicos de processamento de transferência de significado, como também os que embasam-se na concepção cultural, que vê a língua diretamente relacionada à comunidade usuária, seus comportamentos e a interação entre eles, dentre tantas outras correntes. Estes estudos e discussões relacionados à tradução são interdisciplinares, permeando várias áreas do conhecimento.

Talvez a primeira e mais extensa controvérsia sobre a tradução seja a distinção entre "tradução literal" e "tradução livre" que, de acordo com Souza (1998), está consecutivamente centrada na forma ou centrada mais no sentido (nas ideias ou conceitos). A concepção tradicionalista, que está direcionada ao texto na língua fonte, traz um posicionamento de que o tradutor deve valorizar o texto original, exigindo que a formulação do texto traduzido seja simplesmente uma reprodução fiel na língua alvo. Numa perspectiva linguística, "a tradução consistiria em transferir o 'sentido' contido num conjunto de signos linguísticos para outro conjunto de signos linguísticos através do recurso competente ao dicionário e à gramática [...]" (BASSNETT, 2003, p. 35).

Além das concepções relacionadas à tradução em si, existem os questionamentos que envolvem o tradutor, ou seja, posicionamentos que se toma no ato tradutório e que são enfrentados cotidianamente por quem exerce essa atividade. De acordo com Bassnett (2003, p. 47), "o tradutor tem de resolver o problema da não existência de uma convenção parecida em qualquer das culturas de chegada".

Na área os Estudos da Tradução, já há quase cinco décadas vem-se discutindo o conceito equivalência no processo/produção de tradução (WEININGER, 2000; SILVA, 2011) com a finalidade de se contribuir para os critérios e decisões dos tradutores. Durante séculos, a condição hierárquica entre um texto e sua tradução esteve presente nas discussões sobre tradução. A ideia de que o texto traduzido é uma mera cópia do texto original, demonstrando assim "a desigualdade das relações de poder que caracterizam o processo de tradução" (BASSNETT, 2003, p. 7). A autora declara ainda que "um original sempre era visto como superior à sua 'cópia' [...] Como tal, a tradução estava condenada a ocupar uma posição de inferioridade relativamente ao texto de partida do qual se considerava proveniente". 
Assim, a definição de que "a tradução é [...] mais do que a substituição de elementos lexicais e gramaticais entre línguas [...]” (BASSNETT, 2003, p. 54) é deixada em segundo plano e começam a ser levantados problemas de cunho semântico, da intervenção do tradutor que passa a agir como autor, podendo complementar o conteúdo, adaptar o texto ou mesmo omitir mensagens, caso considere irrelevante. Bassnett declara que "[...] o tradutor pode por vezes enriquecer ou esclarecer o texto original como resultado direto do processo de tradução" (BASSNETT, 2003, p. 61).

Nessa perspectiva, o tradutor é entendido como 'autor', o que proporciona espaço para intervenções no texto traduzido. O modelo cognitivo traz a visão de que o tradutor exerce inicialmente a tarefa de 'leitor', ou seja, para que o tradutor produza a mensagem é necessário, antes de tudo, identificar os significados, compreender o sentido do texto base. Sobre isso, Souza (1998) afirma que

toda tradução terá que ser, em primeiro lugar, um processo de identificação e de interpretação/produção de significados, em relação à compreensão leitora do texto original e, em segundo lugar, um processo de substituição e de produção de significados em relação ao texto de chegada (SOUZA, 1998, p. 57).

No decorrer dos estudos, também são analisados aspectos de processo de tradução, o público-alvo do texto traduzido. Em uma perspectiva enunciativo-discursiva, estão presentes as questões relacionadas ao sentido em diferenciação ao significado, proposto principalmente por Bakhtin, como reflexão que transpassa a ato tradutório. Segundo Ponzio

O problema do sentido [...] não se limita à relação entre a língua, como código, e o discurso ou o texto. Também não se limita às relações linguísticas entre os elementos do sistema da língua ou entre os elementos de uma única enunciação, mas ocupa-se das relações dialógicas nos atos de palavra, nos textos, nos gêneros do discurso e nas linguagens (PONZIO, 2008, p. 89).

A tradução de literatura infantil - gênero narrativo - possui características textuais que envolvem a imaginação e subjetividade, no qual estão muito presentes compondo o todo do projeto verbo-visual. A tradução para Libras desse gênero requer a utilização de um enunciado novo, que envolve ressignificações. "Cada um (texto e imagem) tem seus próprios elementos e suas próprias relações proposicionais. Sendo o tradutor de literatura infantil um enunciador destas duas fontes" (ALBRES, 2012, p. 05).

Entende-se que, no ato tradutório estão envolvidos sujeitos (interlocutores) e que a enunciação do tradutor dirige-se a este sujeito, assume-se então que a intersubjetividade está presente na relação entre tradutor e interlocutor(es), cerceando a compreensão da enunciação de todos os envolvidos (BAKHTIN, 2010).

\section{Traduzir é negociar sentidos}

Aprofundando nossos estudos, compreendemos que é consenso de que se deve ultrapassar a unidade frase em processos de tradução e mesmo o texto (tradicional). A tradução envolve aspectos externos ao texto, envolve a leitura e construção de sentidos sobre discursos.

O discurso é uma unidade arquitetônica de produção de sentido que é parte das práticas simbólicas de sujeitos concretos e articulada dialogicamente às suas 
condições de produção, o que envolve seu vínculo constitutivo com outros discursos (SOBRAL, 2009, p.176).

Nessa perspectiva, o material de trabalho do tradutor não é o texto, mas sim discursos. Para o autor, "[...] o discurso é uma unidade de produção de sentido que é parte das práticas simbólicas de sujeitos concretos e articulada dialogicamente às suas condições sóciohistóricas de produção, bem como vinculada constitutivamente (isto é, em sua constituição) com outros discursos" (SOBRAL, 2008, p.58-59).

O tradutor, no papel de leitor especial, constrói sentidos a partir da contrapalavra singular que emana de sua subjetividade, do dialogismo que opera regido pelas suas experiências com a linguagem e com o mundo, ou seja, pelo contexto sócio-histórico particular. Desta forma,

[...] o Círculo reconhece que todo enunciado e todo discurso concretizam um dado feixe de sentidos e afirma que os sentidos sempre se concretizam numa dada circunstância histórica e social que exibe elementos comuns com outras e elementos específicos seus, divergências e acordos, conflitos e harmonia (SOBRAL, 2009, p.90).

Desta forma, o sentido construído por cada leitor é "único", "não reiterável” e "individual". A construção de sentidos é resultado de negociação interna, de atividade responsiva do sujeito como interlocutor envolvido na interação, mesmo que no papel de leitor e tradutor. Quando afirmamos que o sentido é irrepetível, consiste em afirmar que ele não é pronto previamente mesmo que a escrita de um livro esteja materializada. Aquela escrita só toma vida quando é lido por um sujeito em particular.

No processo de leitura e tradução, o profissional atuará com a busca pela correspondência, por "maneiras de dizer uma dada coisa numa língua que correspondem a maneiras de dizer essa mesma 'coisa' em outra língua, algo que varia segundo a época, o lugar, a intencionalidade, o tipo de texto/de discurso etc.”. (SOBRAL, 2008, p.10).

$\mathrm{Na}$ execução do ato tradutório, além do tradutor apropriar-se do texto base, compreendendo-o por completo e inclusive tomando consciência das intenções do autor deste texto/discurso, torna-se imprescindível que o tradutor se posicione perante o texto, imprimindo no texto traduzido suas escolhas discursivas. Assim, o "tradutor é um sujeito social e, portanto, necessariamente produtor de sentidos. Consequentemente, não existe tradução que é espelho do original" (SILVA, 2011, p. 69).

Sobral confirma esse posicionamento, quando declara que

O tradutor não faz simplesmente uma "mutação de palavras de uma língua para outra". Ele reflete e interpreta contextos linguísticos e extralinguísticos em que a palavra está inserida e onde estará depois de traduzida. Traduzir é, assim, uma técnica de sensibilização para as escolhas de expressões a serem utilizadas (SOBRAL et al., 2010, p. 04).

Na tradução há "diversas vozes envolvidas. Nesta concepção, o tradutor é alguém que introduz sua visão de mundo no texto traduzido, assumindo uma postura de autor de seu discurso" (SILVA, 2011, p. 50). O tradutor traz consigo suas impressões do texto original e projeta em suas preferências, elementos que aproximem o texto do público-alvo. Assim, para 
Silva, a autoria é "uma colaboração com um grupo social específico, no qual o autor leva em consideração os valores culturais característicos daquele grupo" (SILVA, 2011, p. 49).

Pretendemos esclarecer até este ponto que a tradução não é uma atividade abstrata, que exima o sujeito que a realiza, ou que seja independente de sua história e subjetividade. Consideramos que esteja envolvido no processo de reconhecimento dos fios de significação e atua ativamente para reorientá-los em sua tradução, envolvido no dialogismo que é inerente à tradução.

\section{Metodologia de pesquisa}

Desenvolvemos uma pesquisa inscrita em abordagem qualitativa, considerando que não nos preocupamos "com representatividade numérica, mas, sim, com o aprofundamento da compreensão de um grupo social, de uma organização, etc." (GERHARDT e SILVEIRA, 2009, p.31).

Focamos na compreensão e explicação de traduções como fenômeno discursivolinguístico. Desta forma, consideramos o estudo da tradução como uma pesquisa "que articula os aspectos linguístico-textuais, que envolvem enunciados, e os aspectos sócio-históricoideológicos de seu objeto, que envolvem a enunciação e, portanto, a situação de enunciação, em seus aspectos de produção, circulação e recepção" (SOBRAL, 2007, p.2109).

O objetivo dos episódios traduzidos analisados foi de produzir conhecimento aprofundado, mesmo que pequeno e circunscrito como um estudo de caso, a compreensão e explicação da dinâmica do processo de construção de sentidos pelo tradutor, levando em consideração aspectos da arquitetônica discursiva (composição enunciativa), sentidos pontuais de termos compreendidos no texto base e empregados pelos tradutores no texto traduzido, como também o gênero a que pertence:

\footnotetext{
O pesquisador não pretende intervir sobre o objeto a ser estudado, mas revelá-lo tal como ele o percebe. $\mathrm{O}$ estudo de caso pode decorrer de acordo com uma perspectiva interpretativa, que procura compreender como é o mundo do ponto de vista dos participantes, ou uma perspectiva pragmática, que visa simplesmente apresentar uma perspectiva global, tanto quanto possível completa e coerente, do objeto de estudo do ponto de vista do investigador (FONSECA, 2002, p. 33).
}

Esta é uma pesquisa aplicada de natureza analítico-descritiva da tradução do livro "Vira Lata" (figura 1), publicado pela editora Brinque Book no Brasil, considerando que apontamos soluções para problemas de tradução de interesse dos profissionais (tradutores), formadores de tradutores e de editores que publicam literatura infanto-juvenil em Libras.

\section{Estabelecimento do corpus e da amostra:}

A tradução foi desenvolvida por estudantes de tradução Libras/Português sob orientação em atividade pedagógica em curso de graduação em Letras/Libras. A atividade envolveu: ( $i$ ) a leitura do material na língua portuguesa (língua de partida); (ii) a discussão coletiva sobre a construção de sentidos e as possibilidades de expressão em língua de sinais (língua da tradução); (iii) filmagem da versão final do texto traduzido, e (iiii) edição dos vídeos sobre as páginas do livro. 
Desta forma, a principal fonte de informações é a tradução coletiva, envolvendo 40 alunos do curso de Letras Libras. A unidade de análise é composta pelos trechos traduzidos. Dentre as 32 páginas do livro, selecionamos um trecho para discorrer neste artigo.

Esta seleção de amostragem permite-nos trabalhar detalhadamente com a descrição dos procedimentos de tradução, sem risco de invalidar resultados ou de impossibilitar a generalização sobre a obra como um todo, visto que ela foi produzida com um perfil tradutório comum.

Procedimentos de pesquisa:

Desenvolvemos os seguintes passos: 1) Leitura da tradução desenvolvida, 2) Seleção de partes da obra para examinar as marcas da interpretação e construção de sentidos na enunciação do tradutor, observando estes elementos nas escolhas tradutórias; 3) Transcrição da tradução, capturando a expressão dos tradutores e a registrando-a em frames de sinalização sobre o programa Word.

Apresentação dos dados:

A tradução foi apresenta inicialmente em uma tabela com três linhas: Primeira linha com a imagem da página do livro; segunda linha com o texto em português escrito; e terceira linha com o frame da sinalização (sinais em sequência congelados), junto a cada sinal um número e a glosa ${ }^{6}$ abaixo. Dessa forma, no processo de análise seria possível retomar um sinal ou outro fazendo referência ao número do frame e o leitor poderia retomar a tabela e verificar a que sinal está se referindo a discussão.

Desenvolvimento do procedimento de análise:

Examinamos, a partir da perspectiva enunciativo-discursiva da linguagem (Teoria Bakhtiniana), a atividade dialógica da tradução considerando na tradução em Libras se o significado do texto-base esteve preservado e disponível para a interpretação do leitor final.

\section{Tecendo os fios de sentido do livro vira lata}

Tomamos como objetivo examinar criticamente as soluções dadas pelos tradutores do ponto de vista da reconstituição de sentidos do texto "Vira Lata", buscando descrever as possibilidades de construção de sentido correspondentes entre o texto base o texto traduzido.

A história "Vira Lata" traduzida é de autoria de Stephen Michael King, uma história infantil que conta sobre um cachorro de rua que passa por muitos desafios para sobreviver. $\mathrm{O}$ cachorro perambula pelas ruas, vive aventuras e busca abrigo em diferentes lugares como: numa praça, embaixo de escadas e bancos e em um abrigo para pessoas, onde não é aceito. Até que uma moça, funcionária do abrigo, lhe dá atenção e começa uma relação afetuosa e de conquista mútua.

Analisamos o episódio dos primeiros contatos da moça com o cachorro (Quadro 1).

Quando a tradução foi editada e sobreposta à página do livro, a visualização que se teve do material foi da apresentação da tradução no canto esquerdo da tela. Assim, o leitor

\footnotetext{
${ }^{6}$ Glosa é a palavra-chave para denominar sinais da Libras em um processo de transcrição em que se atribui palavras em português para registrar os sinais utilizados pelo sujeito de pesquisa em Libras. Segundo McCleary; Viotti; Leite (2010) no sistema de glosas uma palavra em língua oral é grafada em maiúsculo como representação do sinal manual com sentido equivalente. Todavia, nossos dados são em sua maioria compostos por sequência gestual e pantomímica, para esta parte dos dados optamos por registra-la utilizando um texto descritivo/narrativo.
} 
desta nova mídia teve acesso ao português escrito, ilustrações e à Libras como um todo multimodal (Quadro 2).

$\mathrm{O}$ texto "uma moça que trabalhava lá tentou botá-lo para fora mas o cachorro escapou .... e escondeu-se em um canto" (p.16) foi composto pela ilustração de uma moça tomando o cachorro no colo e em movimento (andando). Logo em seguida, abaixo da página, outra ilustração do cachorro embaixo de uma mesa. Os tradutores construíram uma sequência pantomímica seguindo a ordem das duas ilustrações que revelam uma sequência da história narrada.

Consideramos que o texto carrega uma informação e a ilustração carrega outra informação que se convergem para contribuir com a construção de sentido do leitor/tradutor. Podemos dizer que estas duas linguagens, a escrita e a ilustração, complementam-se no processo de leitura. No texto escrito está o "botar para fora", mas como? A ilustração que revela ser pegando-o no colo. Como também no texto escrito está a informação "esconder-se em um canto", mas onde? Na ilustração, encontramos a informação de que é embaixo de uma mesa. Assim, o tradutor, como qualquer leitor, congrega todas estas informações e constrói sua enunciação em Libras.

A questão que colocamos nessa pesquisa está para a correspondência de sentidos do texto-base e do texto da tradução (em Libras). Identificamos diferenças na forma composicional e arquitetônica da expressão, ou seja, a forma de dizer nas línguas foi diferente.

\section{Trecho 1: Uma moça que trabalhava lá tentou botá-lo para fora [...]}

Todo o texto em português constitui-se em texto que configura a expressão do narrador, utilizando da terceira pessoa de forma genérica com a expressão "uma moça" e narra o acontecimento. Todavia, o tradutor escolheu realizar a incorporação da moça e do animal na enunciação em Libras. Então, o tradutor já inicia a enunciação em Libras incorporando a moça que coloca o cachorro para fora.

"Botar para fora" refere-se ao ato de colocar o cachorro para fora do ambiente do abrigo. Em português há algumas expressões que se referem a um circunlóquio próximo deste sentido, havendo uma gradação na força e intenção da ação, podendo-se modalizar a ação ao escolher diferentes termos. Poderíamos dizer em português: expulsar, enxotar, colocar para fora, levá-lo para fora, entre outros.

O sinal expulsar ${ }^{7}$ em Libras construiria um sentido muito forte de raiva contra o cachorro e na história não é esse sentido pretendido pelo autor, considerando que a moça só não poderia deixá-lo ficar no espaço do abrigo, tanto que depois o leva para casa. Portanto, os

${ }^{7}$ SINAL EXPULSAR (1) ou
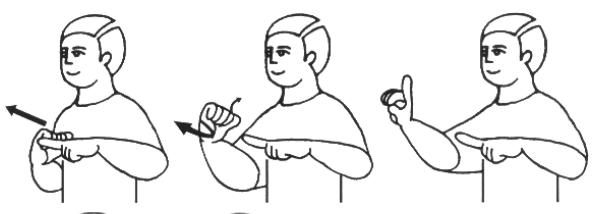

EXPULSAR (2)

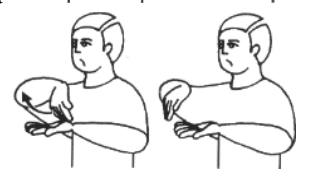

Fonte: Imagens dos sinais retirados de CAPOVILLA; RAPHAEL (2000, p, 639 e 638), respectivamente. 
tradutores escolhem dois gestos para enunciar, como se a moça estivesse empurrando o cachorro para fora do local.

Os tradutores buscaram expressões que em uma arquitetônica enunciativa de incorporação do personagem, em outras palavras, que utilizando-se de discurso direto em Libras, corresponderiam à moça dizendo diretamente ao cachorro: Saia daqui! Utilizando dois gestos: (figura 5).

A palma para cima indica a moça empurrando o cachorro (T2) e a palma para baixo a ação de enxotá-lo (T3). A expressão facial associada aos sinais apregoa à moça um desacordo com a ação que toma para si, ou seja, de ter que colocar o cachorro para fora, tanto que logo em seguida ela o pega no colo para levá-lo para fora do abrigo (T4 e T5).

Adequar a tradução às formas de dizer na língua que está sendo traduzido é fundamental para manter o sentido. Pensando no público-alvo e no momento histórico da tradução, utilizar os sinais para expulsar como registrados no dicionário não atenderiam às formas naturais de enunciação em Libras com o mesmo significado. Ressaltamos que não traduzimos palavras soltas, mas por vezes precisamos nos ater à palavra, principalmente quando há uma polissemia com termos próximos. Minimiza-se a incerteza do significado por meio do contexto e da ilustração. Com outras palavras, o contexto da história narrada e a ilustração desambiguam a incerteza do sentido a ser construído na leitura do sinal/discurso. A seleção que os tradutores fazem revela a sua orientação para o público-alvo do texto e para o personagem que está a construir na narrativa, por meio de pantomimas e da personificação. Esse ato criativo "[...] advém do contexto de vida, que emprega as palavras de julgamentos de valor, impondo pois ao significado uma direção específica: todo discurso é endereçado, dirige-se a alguém e, portanto, traz esse alguém para sua superfície" (SOBRAL, 2009, p.63$64)$.

Constatamos que os tradutores foram cuidadosos ao escolher a expressão em Libras (T2 e T3) pensando no leitor que deve ser envolvido no drama de o cachorro não ter onde ficar e no personagem (moça) que se envolve com o cachorro e afeiçoa-se por ele.

\section{Trecho 2: mas o cachorro escapou .... e escondeu-se em um canto.}

Na sequência, a incorporação é mantida no texto "mas o cachorro escapou". Como o projeto enunciativo do tradutor está constituído pela forma de primeira pessoa que vive o narrado, observe que a moça, com o cachorro em seu colo, desequilibra-se com o movimento do cachorro e solta os braços (T6, T7). Logo em seguida aparece incorporando o cachorro, sozinho e acuado, que olha para cima apreensivo, não mais nos braços da moça (T8), desta forma há uma transferência de papéis. O sinal para escapar ${ }^{8}$ prototípico e dicionarizado não foi utilizado na tradução, mesmo porque o cachorro não escapa e foge para longe, não foge de um perigo, apenas libertar-se indo ao chão. O sentido construído pelos tradutores é o de soltar-se (figura 6).

O leitor da hipermídia estará visualizando esse projeto enunciativo em Libras associado à imagem da menina com o cachorro no colo (figura 7).

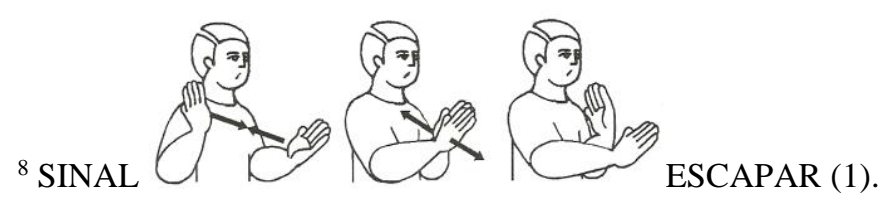

Fonte: Imagens dos sinais retirados de CAPOVILLA; RAPHAEL (2000, p, 598). 
Podemos afirmar que o significado deste trecho do livro "Vira lata" é reportado em Libras em um novo projeto multimodal, enunciado estruturalmente de forma diferente, estrangeiro para o português, mas próximo para os usuários de Libras, ou seja, por meio da criação de espaços mentais próprios de narrativas em línguas de sinais (MOREIRA, 2007). Cabe ao leitor em potencial (surdos) ler e ressignificar o texto, a Libras e a ilustração do livro em uma corrente dialógica e intertextual para construir os sentidos sobre o texto/discurso.

[...] nenhum leitor comparece aos textos desnudados de suas contrapalavras de modo
que participam da compreensão construída tanto aquele que lê quanto aquele que
escreveu, com predominância do primeiro porque no dialogo travado na leitura o
autor se faz falante e se faz mudo nas muitas palavras cujos fios de significação
reconhecidos são reorientados segundo diferentes direções impostas pelas
contrapalavras da leitura (GERALDI, 2010, p. 279).

O tradutor, como um leitor em especial, um leitor entre o autor e leitor final, a quem se destina a obra, deixa marcas de sua leitura, de suas escolhas e de sua visão de mundo no texto que traduz. Da mesma forma, para a expressão "e escondeu-se em um canto" os tradutores buscaram compreender o sentido lendo o texto escrito e a ilustração. Compondo a expressão em Libras pelo particionamento do corpo do tradutor/enunciador (McCLEARY e VIOTTI, 2014). Produzem a seguinte expressão: MESA+ Cachorro incorporado (entrar embaixo) (figura 8).

O sinal de mesa é uma informação do espaço onde ocorre a história. Este sinal é produzido pelo tradutor simultaneamente à expressão facial do cachorro e busca um lugar para se esconder logo depois de ter escapado do colo da moça. Podemos afirmar que em T9 e T10 ocorre o particionamento do corpo do tradutor, em suas mãos está a informação proferida pelo narrador da história (sinal de MESA produzido pelas mãos com círculo vermelho) e em seu corpo e expressão facial estão a ação do cachorro de abaixar-se para entrar embaixo da mesa e o sentimento do cachorro. Assim, mescla em sua enunciação a informação descritiva de objeto que pertence à cena da história ao enunciar MESA com a incorporação do personagem (cachorro), utilizando-se de um projeto enunciativo em que particiona o corpo tradutor em narrador e personagem (figura 9).

Assim, os tradutores constroem a enunciação mantendo o sentido do texto-base, explicitando o local onde o cachorro se esconde com base na ilustração do livro.

\section{CONSIDERAÇÕES FINAIS}

Diferentes sistemas semióticos e dispositivos midiático-digitais convergem para múltiplas experiências estéticas. Este trabalho apresentou a tradução de trechos de livro de literatura infanto-juvenil, analisou-se a forma composicional e arquitetônica escolhida pelo tradutor como atividade estética e a importância a sua preocupação com a leitura em suporte digital, a fim de favorecer a compreensão do processo de incorporação dos personagens, das falas reportadas do particionamento do corpo como apropriados para manter o significado do texto-base criando um espaço para interpretação do leitor em potencial (criança surda).

Nos dois trechos analisados, os cuidados com a direção do corpo do tradutor em comparação à ilustração do livro proporcionam ao leitor a construção de sentido que o corpo do tradutor é uma projeção realística da ilustração do livro, vivenciando o narrado e ilustrado, compondo estética e linguisticamente a obra traduzida. Assim, o tradutor é autor de um novo texto, considerando que sua enunciação irá compor o material midiático. Constatamos que o 
projeto enunciativo do tradutor difere da estrutura do texto-base, contudo garante-se o processo de construção de sentidos.

Por fim, a análise da tradução para a Libras nesse estudo, promoveu a compreensão de que as traduções devem contemplar uma gama de elementos linguístico-discursivos que envolvem a criatividade do tradutor. A partir do endereçamento discursivo para contemplar o processo de significação a ser desenvolvido pelo público.

\section{REFERÊNCIAS}

AGUIAR, Ofir Bergemann. Abordagens teóricas da tradução. Goiânia: Ed. da UFG, 2000.

ALBRES, Neiva de Aquino. Tradução de literatura infantil: entre a construção de sentidos e o uso dos recursos linguísticos. In: Anais do III Congresso Brasileiro de Pesquisas em Tradução e Interpretação de Língua Brasileira de Sinais e Língua Portuguesa. Florianópolis-SC: UFSC. 15 a 17 de agosto de 2012. Disponível em: <http://www.congressotils.com.br/anais/anais_2012.html>. Acesso em: 09 set. 2014.

e Tradução de literatura infanto-juvenil para língua de sinais: dialogia polifonia em questão. Rev. Bras. Linguist. Apl. 2014, v. 14, n.4, pp. 1151-1172. Disponível em: $<$ http://www.scielo.br/scielo.php?script=sci_arttext\&pid=S1984-

63982014000400016\&lng=pt\&nrm=iso\&tlng=en>. Acesso em: 01 abr. 2015.

. O espaço do tradutor em material bilíngue (videolivro): uma análise verbo-visual. In: Anais do IV Congresso Brasileiro de Pesquisas em Tradução e Interpretação de Língua Brasileira de Sinais e Língua Portuguesa. Eixo temático Metodologias para implementar a tradução de/para a língua de sinais. Florianópolis - SC: UFSC. 12 a 14 de novembro de 2014b. Disponível em: <http://www.congressotils.com.br/anais/anais2014.html>. Acesso em: 10 dez. 2014.

ALBRES, Neiva de Aquino; COSTA, Mairla Pereira Pires; ROSSI, Thiago William Teles. Gesto-visualidade no processo de tradução de literatura infanto-juvenil: marcas do discurso narrativo. Revista Tradution. 2015. (no prelo)

BAKHTIN, M. M. Estética da criação verbal. 4. ed. São Paulo: Martins Fontes, 2010.

BASSNETT, Susan. Estudos da Tradução. Lisboa: Fundação Calouste Gulbenkian, 2003.

BRITO, Fábio Bezerra de. O movimento social surdo e a campanha pela oficialização da língua brasileira de sinais. Orientação Rosângela Gavioli Prieto. Tese de doutorado em Educação do Programa de Pós-Graduação da Faculdade de Educação da Universidade de São Paulo. São Paulo: USP, 2013. 275 p.

CAPOVILLA, Fernando Capovilla; RAFHAEL, Walquiria P. Dicionário enciclopédico ilustrado trilíngue da Língua de Sinais Brasileira. v. 1. São Paulo: EDUSP, FAPESP, Fundação Vitae, Feneis, Brasil Telecom, 2000.

FIGUEIREDO, Luciana Cabral; GUARINELLO, Ana Cristina. Literatura infantil e a multimodalidade no contexto de surdez: uma proposta de atuação. In: Revista Educação Especial, Santa Maria. v. 26, n. 45, p. 175-193, jan./abr. 2013.

FONSECA, J. J. S. Metodologia da pesquisa científica. Fortaleza: UEC, 2002. Apostila.

GERALDI, JW. Sobre a questão do sujeito. In: GRENISSA STAFUZZA, Luciane de Paulo. Circulo de Bakhtin: teoria inclassificável. Campinas, SP: Mercado de Letras, 2010. p. 279350.

GERHARDT, Tatiana Engel; SILVEIRA, Denise Tolfo (orgs.). Métodos de pesquisa. Coordenado pela Universidade Aberta do Brasil - UAB/UFRGS e pelo Curso de Graduação Tecnológica - Planejamento e Gestão para o Desenvolvimento Rural da SEAD/UFRGS. Porto Alegre: Editora da UFRGS, 2009. 
GESUELI, Zilda Maria ; Moura, L. de . Letramento e Surdez: a visualização das palavras. ETD. Educação Temática Digital, v.7, p. 110-122, 2006. Disponível em: < http://www.fae.unicamp.br/etd/include/getdoc.php?>. Acesso em: 17 fev.2015.

KING, Stephen Michael. Vira Lata. Trad. Gilda de Aquino. São Paulo: Brinque-Book, 2005. McCLEARY, Leland; VIOTTI, Evani; LEITE, Tarcísio de Arantes. Descrição das línguas sinalizadas: a questão da transcrição dos dados. Revista Alfa: São Paulo, 2010.

McCLEARY, Leland; e VIOTTI, Evani. Espaços integrados e corpos partidos: vozes e perspectivas narrativas em línguas sinalizadas. Scripta, PUC Minas, Belo Horizonte, v. 18, n. 34, 2014.2 Disponível em: <http://periodicos.pucminas.br/index.php/scripta/article/viewFile/8781/pdf >. Acesso em: 28 mar. 2015.

MOREIRA, Renata Lucia. Uma descrição de Dêixis de Pessoa na língua de sinais brasileira: pronomes pessoais e verbos indicadores. Dissertação de mestrado em Linguística. Faculdade de Filosofia, Letras e Ciências Humanas (FFLCH)- USP, 2007.

PONZIO, Augusto. A revolução bakhtiana: o pensamento de Bakhtin e a ideologia contemporânea. São Paulo: Contexto, 2008.

SILVA, Heber de Oliveira Costa E. Tradução e dialogismo: um estudo sobre o papel do tradutor na construção do sentido. Recife: Ed. Universitária da UFPE, 2011.

SOBRAL, Adail U. Um diálogo bakhtiniano com L. A. Marcuschi. In: Anais IV Simpósio internacional de estudo de gêneros textuais - SIGET, Tubarão SC: UNISUL, 2007. p. 21062112. Disponível em:

$<$ http://linguagem.unisul.br/paginas/ensino/pos/linguagem/eventos/cd/Port/144.p > $\underline{\text { dfAcesso }}$ em: 10 mar. 2015.

2008.

Dizer o "mesmo" a outros: ensaios sobre tradução. São Paulo: SBS Editora,

Autoria e estilo: forma composicional e forma arquitetônica. In: Do dialogismo ao gênero: as bases do pensamento do círculo de Bakhtin. Campinas - SP: Mercado das Letras, 2009. p. 61-72. Cap. 3.

SOBRAL, Adail; GOMES, Francine de Oliveira; VAZ, Raquel Menezes; AZEVEDO, Roberta Quintanilha; FELIX, Sylvia Furtado. Tradução: a (re)produção do sentido. Anais do IX Encontro do CELSUL-Círculo de Estudos Linguísticos do Sul. Palhoça, 2010. Disponível em: <http://www.celsul.org.br/Encontros/09/artigos/Adail\%20Sobral.pdf >. Acesso em: 17 de fev. 2015.

SOUZA, José Pinheiro. Teorias da tradução: uma visão integrada. Rev. de Letras, v. 1/2, n. 20, jan/dez. 1998. Disponível em: 〈http://www.revistadeletras.ufc.br/rl20Art09.pdf〉. Acesso em: 20 mar. 2015.

VASCONCELLOS, Maria Lúcia. Tradução e interpretação de língua de sinais (TILS) na pósgraduação: a afiliação ao campo disciplinar "estudos da tradução". In: Cadernos de Tradução. Florianópolis. 2010,v. 2, n. 26, p. 119-143. Disponível em: <http://www.periodicos.ufsc.br/index.php/traducao/article/view/2175-7968.2010v2n26p119>. Acesso em: 20 de mar de 2015.

WEININGER, Markus J. Estrela guia ou utopia inalcançável: uma breve reflexão sobre a equivalência na tradução. In: CARDOZO, Maurício; HEIDERMANN, Werner; WEININGER, Markus J. (org.). A Escola Tradutológica de Leipzig. Frankfurt/Main: Peter Lang Verlag, v. 1, 2009. p. 19-28.

Recebido 10-04-2015

Aprovado 12/2016 


\section{ANEXOS}

Figura 1. Capa do livro "Vira lata" de Michael King (2004). Editora Brinque Book

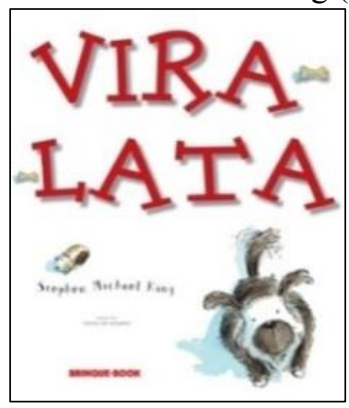

Fonte: KING (2005)

Figura 2. Visualização da página do livro impresso. Trecho da página traduzida

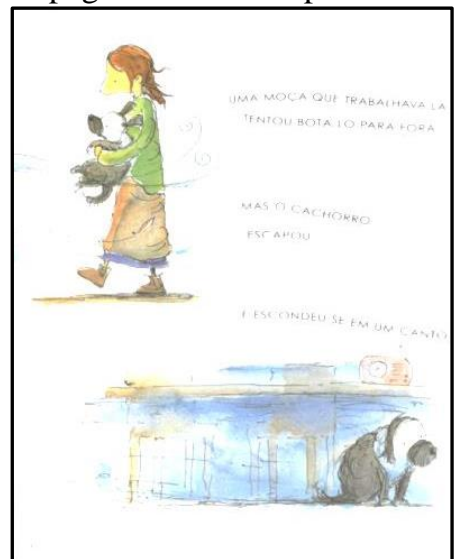

Fonte: KING (2005)

Figura 3. Visualização da tela no computador

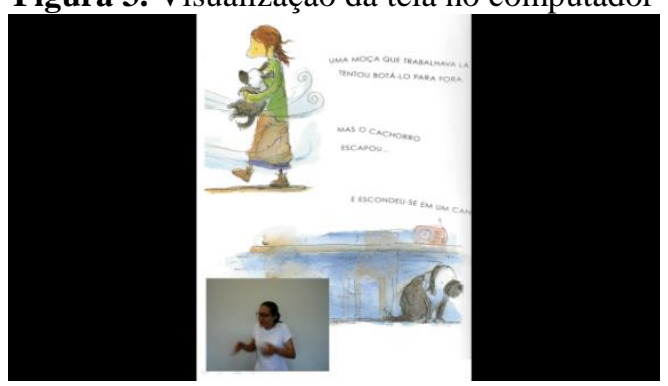

Fonte: autor 
Figura 4. T12 Sequência da tradução para Libras.

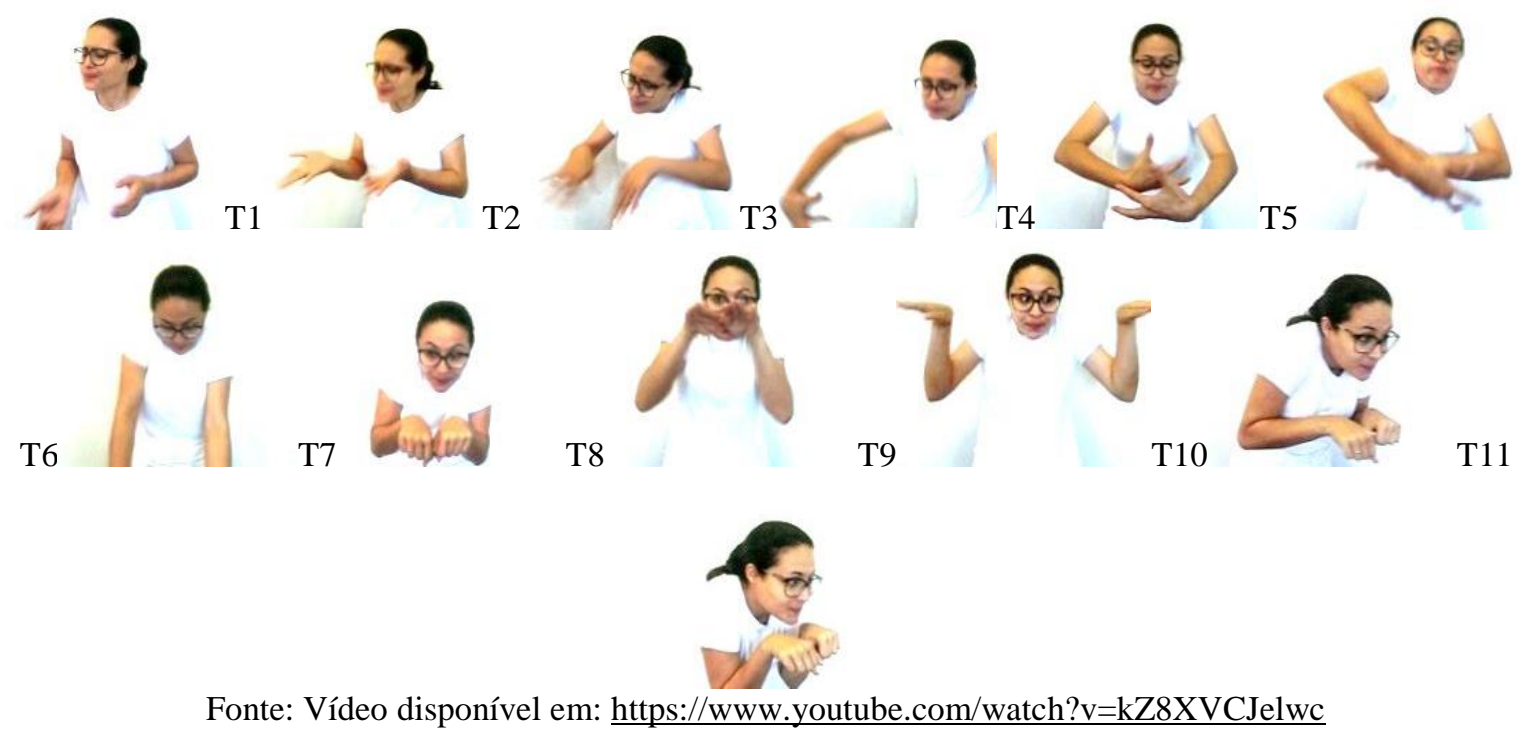

Figura 5. Moça incorporada - (enxota o cachorro e o pega no colo)

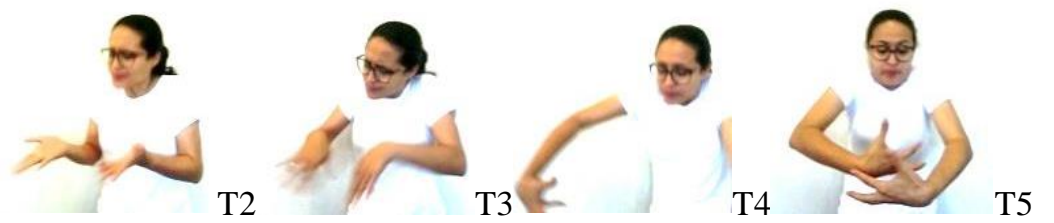

Fonte: Vídeo disponível em: https://www.youtube.com/watch?v=kZ8XVCJelwc

Figura 6. Moça incorporada - (segurando o cachorro) + Cachorro incorporado - (no chão)

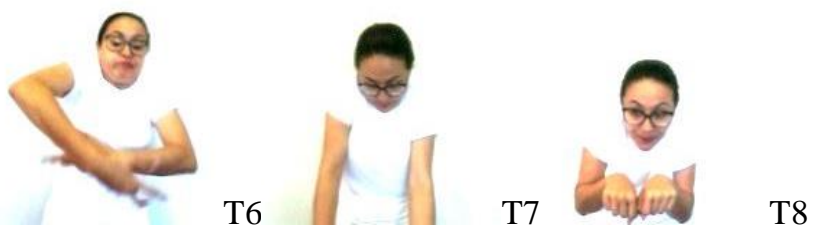

Fonte: Vídeo disponível em: https://www.youtube.com/watch?v=kZ8XVCJelwc

Figura 7. Ilustração do livro (p.16- primeira parte) 


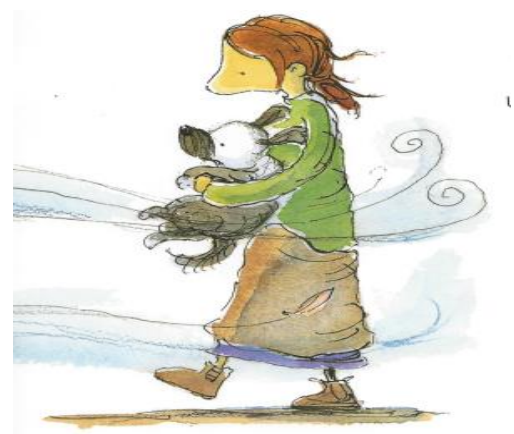

Fonte: KING (2005)

Figura 8. Narrador - MESA + Cachorro incorporado (esconde-se embaixo da mesa quietinho)

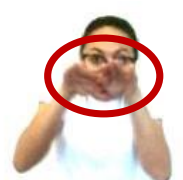

T9

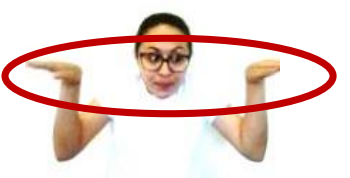

$\mathrm{T} 10$

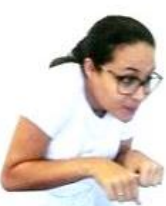

T11

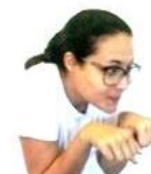

$\mathrm{T} 12$

Fonte: Vídeo disponível em: https://www.youtube.com/watch?v=kZ8XVCJelwc

Figura 9. Ilustração do livro (p. 16- segunda parte)

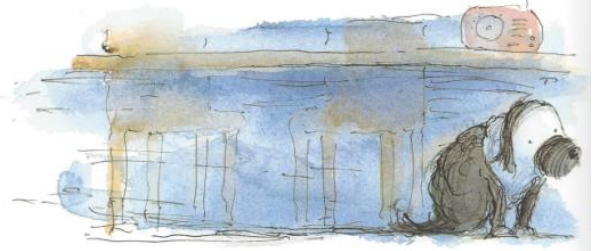

Fonte: KING (2005)

Quadro 1: Comparação entre os dois suportes materiais com e sem a tradução para a Libras.

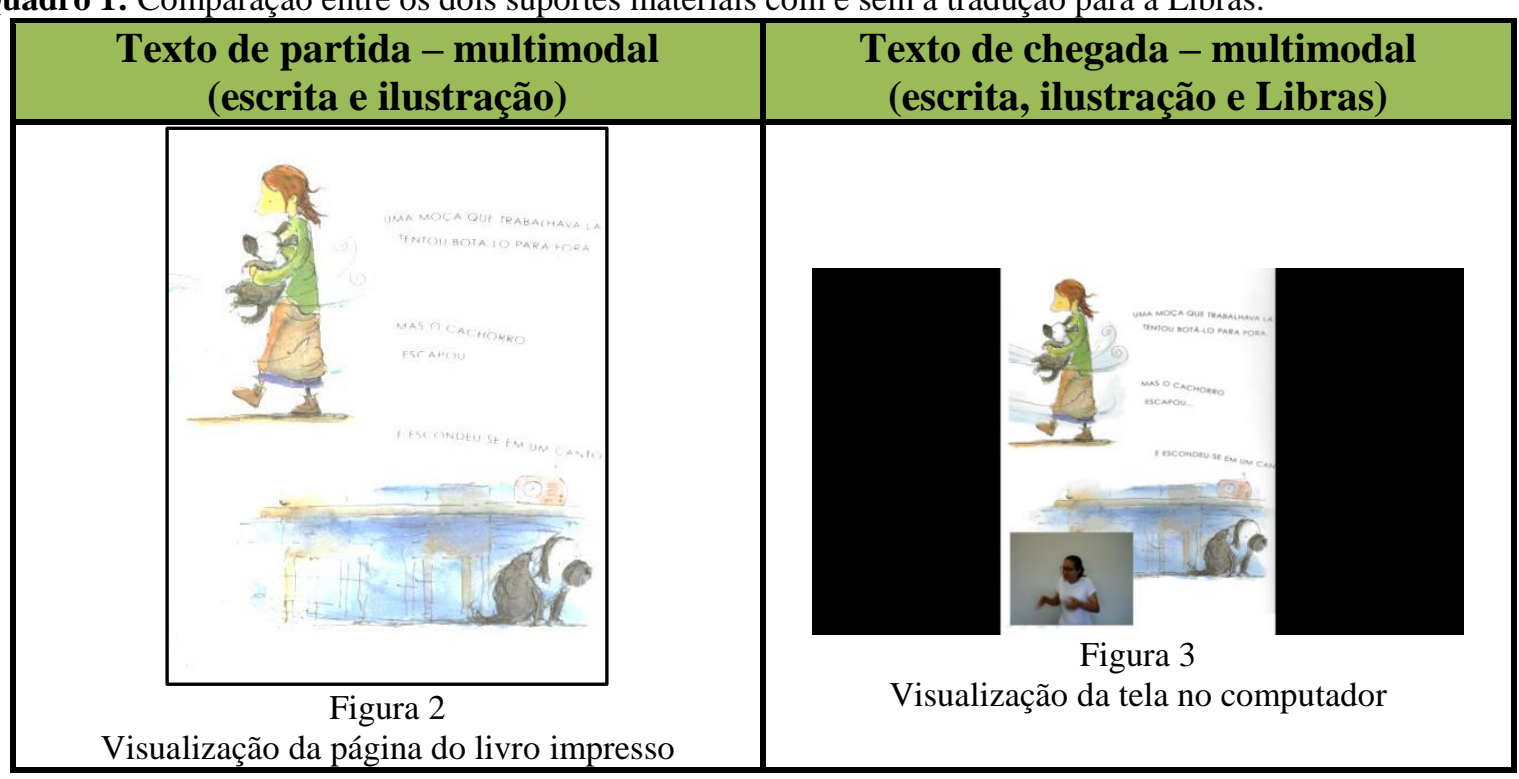

Educação e Fronteiras On-Line, Dourados/MS, v.7, n.19, p.19-35, jan./abr. 2017 
Trecho da página traduzida

Fonte: KING (2005)

Quadro 2: Comparação entre material linguístico em português escrito e em Libras

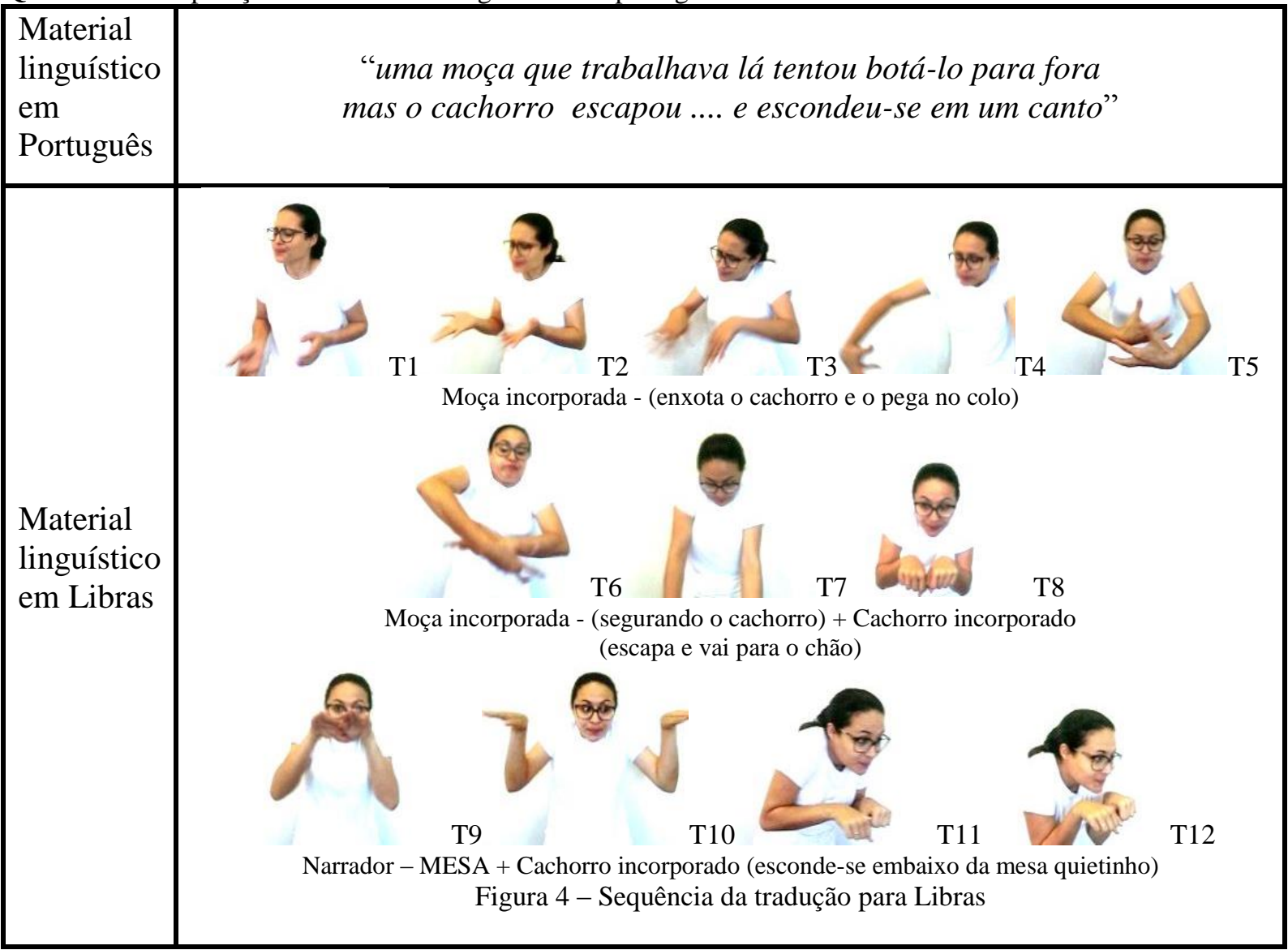

Fonte: Vídeo disponível em: <https://www.youtube.com/watch?v=kZ8XVCJelwc> 